\title{
Elementos de profissionalidade em livros de Desenho Linear do século XIX
}

\author{
Elements of professionality in nineteenth-century Linear Drawing books
}

Maria Cristina Araújo de Oliveira ${ }^{1}$

\begin{abstract}
Resumo
$\mathrm{O}$ artigo investiga elementos de profissionalidade identificados em quatro manuais escolares brasileiros de Desenho Linear para o ensino primário e normal do século XIX. Essa noção considera os conteúdos e a adequação deles aos alunos em cada série - nível de escolaridade, os métodos para aprendizagem, os materiais indicados, entre outros aspectos. Procurou-se identificar, além dos saberes a ensinar, os conteúdos objeto de trabalho dos professores e os saberes para ensinar, ou seja, aqueles que mais diretamente se alinham à profissão docente. O Desenho Linear a ensinar em todos eles referem-se ao estudo das figuras planas - linhas, polígonos e curvas -; e dos poliedros e corpos redondos, sem a preocupação com o cálculo de grandezas como perímetro, área e volume. As marcas específicas de cada uma das obras analisadas ficam mais evidentes no que diz respeito às questões metodológicas - Desenho Linear para ensinar.
\end{abstract}

Palavras-chave: desenho linear, profissionalidade, desenho para ensinar, desenho a ensinar.

\begin{abstract}
The article investigates elements of professionality identified in four Brazilian textbooks of Linear Drawing for elementary school and its teacher's training in the nineteenth century. This notion considers the contents and the adequacy of the same to the students in each series - level of schooling, the methods for learning, the indicated materials, among other aspects. It also sought to identify beyond the Linear Drawing as a subject, the knowledge to teach, those that are most directly aligned with the teaching profession. The Linear Drawing to teach in all of them refers to the study of plane figures - lines, polygons and curves -; and polyhedra and round bodies, without concern for the calculation of quantities such as perimeter, area and volume. The specific marks of each one of the analyzed works become more evident with respect to the methodological questions - Linear Design to teach.
\end{abstract}

Keywords: linear drawing, professionality, drawing as a subject, drawing to teach.

\section{Introdução}

O presente artigo tem como objetivo discutir quais profissionalidades para o ensino de desenho no primário no século XIX podem ser identificadas em livros que tratam desse saber destinados aos alunos tanto do primário quanto das escolas normais.

A partir das conceituações de Bourdoncle (1991), Hofstetter e Schneuwly (2009) e André e Almeida (2010) sobre a profissionalidade temos tomado tal noção como possibilitadora de desenvolvimento profissional permitido por meio da apreensão de saberes

\footnotetext{
Submetido em: xx/xx/xxxx - Aceito em: 23/05/2019 - Publicado em: 23/05/2019

${ }^{1}$ Doutora em Educação (Currículo) pela PUC-SP. Professora Associada do Departamento de Matemática e do PPG em Educação Matemática da UFJF, Brasil. Email: mcrisoliveira6@ gmail.com.
} 
DOI: $10.20396 /$ zet.v27i0.8654266

racionalizados sobre o ensino de geometria ou de desenho. Tais saberes levam em conta os conteúdos e a adequação dos mesmos aos alunos em cada série - nível de escolaridade, os métodos para aprendizagem, os materiais indicados, entre outros aspectos (OLIVEIRA, 2015a, 2016, 2018).

Neste texto, nos interessa caracterizar saberes que participam da formação dos professores primários que estão sistematizados em livros de Desenho Linear. Particularmente nos interessa apreender a partir das obras examinadas saberes sistematizados sobre o conteúdo para o ensino de Desenho Linear, as propostas metodológicas sistematizada ou mesmo a ausência das mesmas, os materiais indicados e a indicação de uso destes, entre outros aspectos que podem ser entendidos como possibilitadores de um conhecimento para ensinar Desenho Linear.

Em consonância com Hofstetter e Schneuwly (2009), consideramos que a profissionalidade é marcada pelo exercício de teorização pedagógica e didática, que conduz a uma formalização da própria prática. Ao longo do processo de profissionalização da docência, um conjunto de saberes vão constituindo a profissionalidade, saberes que são próprios ou compartilhados e participam da formação da identidade profissional "em função do público e do grau escolar, em função dos conteúdos e disciplinas de ensino, em função do vínculo institucional e do status profissional" (HOFSTETTER; SCHNEUWLY, 2009, p. 17. Tradução nossa.).

Neste artigo analisamos quatro livros de Desenho Linear publicados no século XIX, com o objetivo de identificar elementos de profissionalidade para o ensino desse saber. $\mathrm{O}$ Desenho Linear teve um papel importante no processo de institucionalização da escola primária e na formação dos normalistas no século XIX. Tais obras são representativas da publicação nacional sobre o assunto no período, embora haja outras também importantes. Vários trabalhos já se debruçaram sobre esses livros, orientados por questões outras que não a profissionalidade.

\section{As Escolas normais e a formação de professores primários: saberes profissionais}

No século XVII a formação de professores já era uma preocupação manifesta de Comenius, cientista, pedagogo, educador e escritor tcheco considerado o pai da didática moderna. João Batista de La Salle, padre e pedagogo francês que consagrou a vida a ensinar crianças pobres, instituiu no ano de 1684, na cidade francesa de Reims, o primeiro estabelecimento destinado à formação de docentes com o nome de Seminário dos Mestres.

No século XVIII, particularmente na França no contexto da Revolução de 1789, se intensificam os debates sobre a instrução popular e a necessidade de criação de escolas encarregadas de preparar os professores que seriam corresponsáveis pelas transformações exigidas pela sociedade. Assim, instalou-se em Paris no ano de 1795 a primeira escola normal. Nesta época, já se fazia uma distinção entre escola normal superior, destinada a formar os professores para atuarem no ensino secundário e nas escolas normais primárias, e a 
DOI: $10.20396 /$ zet.v27i0.8654266

escola normal primária, que prepararia os mestres para atuarem na escola primária. Ao longo do século XIX, outras escolas normais foram instituídas em países da Europa e nas Américas. (SAVIANI, 2009).

A trajetória de formação de professores primários nos cantões suíços de língua francesa é estudada por Borer (2017). A autora identifica dois sistemas; o das escolas normais e aquele que se dá nas universidades. Cada um dos modelos é adotado em distintos cantões. A pesquisa aponta que o modelo das escolas normais, realizado sob o controle da administração escolar, "tem pouca ligação com as ciências da educação presentes no nível universitário" (BORER, 2017, p. 178). Enquanto que o modelo "superior", realizado nas universidades, pressupõe uma formação generalista em nível secundário, atendo-se à formação profissional.

Assim, a formação geral ligada às disciplinas escolares dominam nas escolas normais, enquanto que a formação profissional caracteriza o modelo empreendido no ensino superior. Neste caso, os saberes para ensinar, "(principalmente os ensinos de pedagogia teórica e prática, de psicologia, de ciências da educação) aos quais se unem ainda todas as didáticas/metodologias das diferentes disciplinas escolares", constituem a essência (BORER, 2017, p. 180).

No Brasil após a Independência, em 1822, se ascende o debate em torno da organização da instrução popular, e a referência oficial à formação dos professores aparece pela primeira vez em 15 de outubro de 1827 com a promulgação da Lei das Escolas de Primeiras Letras, que instituía o ensino pelo método mútuo. Em seu artigo $6^{\circ}$, essa lei dispõe sobre o que os professores deveriam ensinar em relação à matemática, "as quatro operações da aritmética, prática de quebrados, decimais e proporções e as noções mais gerais de geometria prática" e, para atuarem como professores, os candidatos deveriam ser aprovados em exames das matérias de ensino incluindo as anteriormente referidas (RIO DE JANEIRO, 1827, p. 72).

Em 1834, com a promulgação do Ato Adicional, a instrução primária ficou sob a responsabilidade das províncias que adotaram o modelo das escolas normais para a formação dos professores. No ano seguinte, foi instituída no país a primeira escola normal na província do Rio de Janeiro, na cidade de Niterói, o que deu início a uma grande expansão desses estabelecimentos, fazendo surgir escolas em diversas outras províncias, como Minas Gerais (1840) e São Paulo (1846). As escolas normais tinham uma formação específica, já que o objetivo era a preparação de professores para a escola primária, e, por isso, constavam de seu currículo as mesmas matérias que seriam ensinadas nas escolas de primeiras letras. A importância maior era dada a esses conteúdos que os professores deveriam dominar em detrimento do preparo didático-pedagógico (TANURI, 2000).

Em período posterior, a partir de 1875 até a década de 1930, Valente (2011) mostra como a presença da trigonometria como matéria de ensino autônomo na formação de normalistas paulistas é indicativa de uma alternância entre a formação de caráter propedêutico, generalista, e aquela voltada à formação profissional. $O$ destaque à 
trigonometria no currículo das normalistas paulistas coincide com os períodos de formação generalista.

Um fato determinante para a organização e funcionamento das escolas normais foi a reforma da instrução pública do estado de São Paulo, a partir da década de 1890. Segundo os propositores, só a boa formação dos professores garantiria um ensino "regenerador e eficaz", e essa formação caberia às escolas normais. A reforma possibilitou tanto o enriquecimento dos conteúdos curriculares quanto uma maior atenção aos exercícios práticos de ensino. Posteriormente, tornou-se referência para outros estados do Brasil, havendo um intercâmbio entre educadores que iam estagiar em São Paulo ou educadores paulistas que participavam da reestruturação do ensino em outros estados do país. Esse período dá início a um processo de valorização da institucionalização de saberes específicos para a docência.

Hofstetter e Schneuwly (2009) organizam uma publicação cujo título traduzido indica a centralidade da obra sobre os saberes para a profissão de ensino e a formação dos professores - Saberes em (trans)formação: tema central da formação de professores ${ }^{2}$.

A importância dos saberes liga-se à finalidade primeira da escola, que é a aprendizagem. A escola em sua essência é um lugar de aprendizagem.

Este foco sobre a aprendizagem como atividade específica que encontra sua finalidade em si própria parece uma evidência para a instituição escolar na sua concepção tradicional [...] De fato, esta escola tem como primeira meta a formação geral, a transmissão de uma cultura geral [...] (HOFSTETTER; SCHNEUWLY, 2017, p. 118).

Na perspectiva da instituição escolar como um local de aprendizagens intencionais, os autores optam por centrar a investigação sobre os saberes formalizados que participam da formação de professores. Tais saberes não são aqueles mobilizados no fazer, eles são fruto de teorização, são saberes objetivados. E referindo-se a estes citam Barbier (1996), explicitando que tais saberes remetem

a realidades com o estatuto de representações [...] dando lugar a enunciados proposionais e sendo objeto de uma valorização social sancionada por uma atividade de transmissão-comunicação. Elas, esses representações, têm consequentemente uma existência distinta daqueles que as enunciam ou daqueles que delas se apropriam. São conserváveis, acumuláveis, apropriáveis (BARBIER, 1996, p. 9 apud HOFSTETTER; SCHNEUWLY, 2017, p. 131).

A partir de tais considerações poderíamos interrogar: quais vestígios do passado possibilitariam apreender tais saberes? Ou ainda, que espécie de documentos, entendidos numa perspectiva mais abrangente como nos coloca Le Goff (1992), possibilitariam um estudo histórico sobre a constituição de saberes formalizados para ensinar matemática? Mais particularmente, para ensinar Desenho no ensino primário?

\footnotetext{
${ }^{2} \mathrm{O}$ título traduzido é do livro publicado em 2017 sob a organização de Hofstetter e Valente, que contém a tradução de três capítulos do original em francês Savoirs en (trans)formation, publicado em 2009, organizado por Hofstetter e Schneuwly.
} 
DOI: $10.20396 /$ zet.v27i0.8654266

Para Hofstetter e Schneuwly (2009), dois tipos de saberes são constitutivos da profissão docente: os saberes a ensinar, que são objeto do trabalho docente, que dizem respeito aos conteúdos ou disciplinas, como a matemática; e os saberes para ensinar, que são as ferramentas para a ação docente, que compreendem metodologias, materiais didáticos, sequências para o ensino.

Valente (2017) traz reflexões específicas para a matemática, considerando a matemática a ensinar e para ensinar como saberes da formação do professor que ensina matemática. Tomando como referência as transformações ocorridas no ensino primário e no normal a partir da organização dos grupos escolares no Brasil, em fins do século XIX, destaca-se a relevância dos saberes para ensinar matemática que se evidencia em obras didáticas e manuais para professores. "O saber para ensinar matemática constitui-se a partir desse tempo como a ciência de formas intuitivas para a docência dos primeiros passos da aritmética e da geometria" (VALENTE, 2017, p. 216). A partir de referências como a Pedagogia de Pestalozzi, a obra Primeiras Lições de Coisas de Calkins, traduzida por Rui Barbosa, e de outros escritos dele como os Pareceres sobre a reforma do ensino primário, as publicações destinadas ao ensino primário e normal se apropriam dessas discussões e sistematizam uma matemática para ensinar intuitivamente.

\section{O Desenho na formação dos professores primários: elementos de profissionalidade}

A presença da disciplina Desenho em cursos normais ${ }^{3}$ de diferentes estados do Brasil foi objeto de estudo em Oliveira (2015b). O estudo possibilitou identificar a prevalência do Desenho sob diferentes especialidades, - geométrico, de paisagem, linear, natural - nos programas de ensino para os tais cursos. Os primeiros programas datam do final do século XIX e a primeira década do XX na maioria dos estados brasileiros e contemplam o Desenho como disciplina em todos os anos de formação, ou na maior parte deles. É o caso dos estados da região sul e sudeste do Brasil, cujas normativas foram analisadas no referido estudo.

O desenho linear parece ser o modelo que vai predominar, ocupando um papel de destaque na formação e participando como matéria de praticamente todos os anos do curso normal. $\mathrm{O}$ desenho desempenha uma função prática relevante de educar a vista e adestrar a mão - em muitos casos o desenho vem junto à caligrafia como disciplina. (OLIVEIRA, 2015b, p. 52)

Analisamos a seguir quatro obras de Desenho Linear que circularam em diferentes estados do Brasil e referenciaram o ensino em cursos normais. Buscou-se identificar nelas elementos de profissionalidade sistematizados pelos autores com base em concepções acerca do ensino de Desenho Linear.

Uma das primeiras obras sobre Desenho publicadas no Brasil foi "Princípios do Desenho Linear compreendendo os de Geometria Prática, pelo método do ensino mútuo",

\footnotetext{
${ }^{3}$ Curso normal é o que tem lugar nas escolas normais.
} 
extraídos de L. B. Francoeur, de autoria de Antônio Francisco de Paula e Iollanda Cavalcanti d'Albuquerque, 1829.

Nas suas páginas iniciais, o autor esclarece que foi elaborado para facilitar aos professores públicos a execução da Lei das Escolas de Primeiras Letras, publicada em 15 de outubro de 1827, que instituía o ensino pelo método mútuo, como já mencionamos. Os princípios apresentados na obra foram extraídos do livro Desenho Linear de Benjamin Francoeur ${ }^{4}$, publicado na França em 1819. Essa obra, segundo Trinchão (2007) e D’Enfert (2007), caracteriza-se num manual de didático de desenho.

No livro, o autor descreve detalhadamente procedimentos para o ensino: escolha de um grupo de alunos entre os mais inteligentes (que seriam os decuriões), que receberiam as lições diretamente do professor e passariam aos demais alunos (discípulos). Os materiais requeridos para o ensino também são minuciosamente especificados: ardósia; lousas a serem pregadas nas paredes; suportes de madeira para os modelos a serem copiados pelos alunos; metros pregados ou mesmo desenhados no alto das lousas; réguas para conferência pelos decuriões do desenho realizado pelos alunos; outros instrumentos de conferência como o esquadro e o compasso.

Não se suponha grande diferença de conhecimento sobre assunto entre o professor, o decurião e os alunos, a imitação era a base do método. Citando Pestalozzi, o autor destaca que o exercício com o traçado deveria preceder a formação das letras. Contudo, D'Albuquerque (1829) recomenda aos professores que o ensino do Desenho Linear se destinaria somente às últimas classes das escolas de primeiras letras, "não só por considerarmos estas mais desenvolvidas, como por economizar o tempo nesta especie de instruccção" (D’Albuquerque, 1829, p. 6).

A diferença do ensino aplicado aos decuriões e aos estudantes em geral pode ser exemplificada em instruções sobre o significado de termos da Geometria como diâmetro, paralela, retângulo, que seria ensinado somente aos decuriões. Os demais discípulos aprenderiam por observação e imitação o significado dos mesmos. O autor descreve o que deveria ser proposto, os problemas de construção, para cada uma das quatro classes do ensino primário. A exposição compreende o enunciado, por exemplo, em uma lição da $4^{\mathrm{a}}$ classe “Traçai huma recta, que seja tangente á dous círculos, fig. 1" (D’Albuquerque, 1829, p. 55). Em seguida, o autor descreve propriedades que decorrem da construção - os respectivos raios das circunferências perpendiculares à tangente serão paralelos. É importante destacar que não há uma descrição de como fazer a construção, somente as características que a figura construída deve possuir.

\footnotetext{
${ }^{4}$ Louis-Benjamin de Francoeur (1773-1849), autor do compêndio Le Dessin Linéaire d'aprés la méthode de l'enseignement mutuel, publicado em 1819. Segundo Trinchão (2007) o manual de Francoeur contribuiu para a vulgarização do Desenho escolar.
} 


\section{QUARTA CLASSE.}

1. Traçai huma recta, que seja tangente do dous

- circulos, fig. 1. He preciso fazer, com que os raios trazidos aos dous pontos de contacto, sejào perpendiculares á tangente, e por consequencia parallelos. Observe-se, que pode fazerse, que os circulos dados se cortem, ou sejāo - separados hum do outro; os discipulos devem exercitar-se nestas duas hypotheses.

Quando accontece, fque os raios de duas circunferencias, fig. 1," sāo iguaes, a tangente he então parallela á recta, que une os centros. Assim de dous centros quaesquer tomados sobre a linha dada; e com o mesmo raio traçai dous arcos de circulo; a recta, que tocar hum e outro pela paryte exterior será parallela á linha doscentor of he este ainda hum meio de resolver a seguinte questão: tirar huma recta parallela d" outras:

Figura 1: construção da tangente a dois círculos Fonte: d'Albuquerque, 1829, p. 55.

No final do livro encontram-se os enunciados de todos os desenhos a serem construídos por classe, e as figuras que seriam obtidas para cada enunciado.

Os elementos de profissionalidade percebidos nessa obra tratam tanto de saberes a ensinar, como os que dizem respeito aos assuntos, conteúdos, explorando conceitos geométricos via desenho, quanto saberes para ensinar, que indicavam aos mestres os passos para o ensino, as possibilidades de diferentes abordagens, os modos de verificação da aprendizagem, os materiais necessários e como usá-los, entre outros.

Uma segunda obra examinada é o livro "Elementos de Desenho Linear", $2^{a}$ edição melhorada (como consta na capa) de 1880. O compêndio do professor Ayres de Albuquerque Gama foi aprovado pela Escola normal de Pernambuco para uso dos alunos - mestres, onde era professor, conforme consta também da capa.

$\mathrm{Na}$ introdução o autor explica que

O desenho linear é a arte de representar os objectos, indicando os seus contornos por meio de linhas. [...] Sendo o seu fim principal representar os productos das industrias e artes, basea-se o desenho linear sobre os principios geometricos, pelo que deve ser considerado como applicação da geometria (GAMA, 1880, p. 1).

O Desenho Linear para o autor se divide em gráfico e geométrico. Este último mais exato na construção das figuras, pois se utiliza dos instrumentos da matemática: régua, 
DOI: $10.20396 /$ zet.v27i0.8654266

compasso, esquadro, transferidor, escala de proporção, pantógrafo, elipsógrafo e régua flexível.

A obra está organizada em três partes: figuras planas, figuras no espaço e arquitetura. Em cada parte os conceitos geométricos e as construções aparecem combinadas. Por exemplo, no capítulo sobre polígonos, após explicar o que são os polígonos e seus respectivos nomes, o autor explica o que é bissetriz de um ângulo e como construí-la, usando o transferidor e também o compasso. No caso do compasso apresenta um roteiro da construção.

Os polígonos regulares e estrelados são aplicados na construção de mosaicos. Como ilustrado na Figura 2.

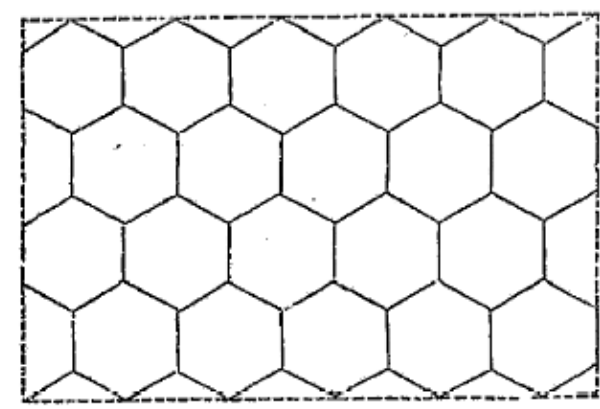

Fig. 60 .

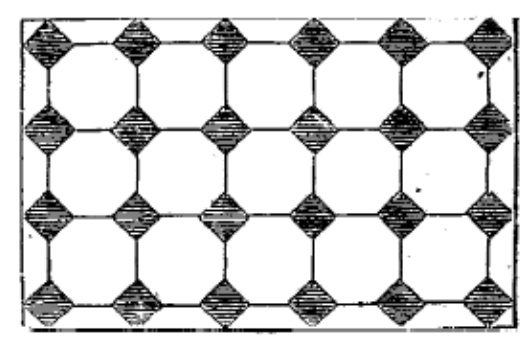

Tig. 61 .

A combinação dos polygonos regulares e dos estrellados tem uma grande applicação nos trabalhos em mosaico.

As figuras $58,59,60$ e 61 mostraืo as applicações dos triangulos, quadrilateros, e polygonos regulares.

Figura 2: mosaicos de polígonos

Fonte: Gama, 1880, p. 32.

As figuras no espaço são trabalhadas juntamente com o estudo dos sólidos - poliedros e corpos redondos - a perspectiva e a projeções geográficas - projeção estereográfica, projeção por equidistâncias, projeção de Flamsteed e projeção mista.

$\mathrm{Na}$ arquitetura são apresentados diferentes estilos de partes de construções, tais como colunas, molduras, frontispícios. As relações com a geometria e as construções com compasso são explicitadas em cada um dos exemplos.

Nessa obra as profissionalidades referem-se a conceitos de geometria articulados com suas construções com os instrumentos de desenho. Não há orientações mais detalhadas sobre o método de ensino, o detalhamento diz respeito ao conteúdo, à geometria ou ao desenho a ensinar.

Outra obra analisada é o livro "Curso Elementar de Desenho Linear", organizado sobre os trabalhos dos melhores autores, de Paulino Martins Pacheco, 1881, engenheiro agrimensor e professor na Escola normal e no Internato do Imperial Colégio Pedro II. 
No prefácio, o autor destaca a importância do Desenho Linear por ser necessário a todas as profissões. Faz menção à obrigatoriedade do ensino desse saber em países da Europa e nos Estados Unidos. Aponta a divisão do Desenho Linear em: linear à vista e linear gráfico. Ao segundo pesa a exigência do uso dos instrumentos e das escalas.

O livro é constituído de três partes que, diferentemente da obra anterior, separam o desenho à vista do gráfico, das aplicações. No Desenho Linear à vista são abordados em três capítulos as linhas retas e curvas, entre elas a circunferência, a elipse, a parábola, a hipérbole -; as superfícies, círculos e polígonos; os corpos, poliedros e corpos redondos. No Desenho Linear gráfico, após apresentar os instrumentos, são trabalhadas as curvas - circunferência, elipse, parábola, hipérbole, ligação de linhas curvas - e os polígonos. As aplicações compreendem desenho de produtos industriais, tais como mosaicos e desenho de arquitetura - colunas, frontões, etc.

Embora os conteúdos apresentados nas duas obras anteriormente comentadas, Gama (1880) e Pacheco (1881), sejam bastante semelhantes, elas diferem na metodologia. A primeira articula o estudo das figuras com a construção, não separando as propriedades da construção das mesmas, separando figuras planas das espaciais. Na segunda, a separação é entre o que é estudado sem os instrumentos, somente pelo "golpe de vista", do que é construído com os instrumentos - régua, compasso, etc.

No livro de Pacheco (1881), os elementos de profissionalidade identificados também dizem respeito a conceitos de geometria e sua construção com os instrumentos, porém separando a figura da sua construção. Por exemplo, no estudo do triângulo, primeiro ele é apresentado a partir dos diferentes tipos em função dos ângulos e de algum segmento notável - altura -; na parte 2, a construção do triângulo mediante diferentes condições é apresentada: equilátero, isósceles, retângulo.

Por último analisamos o livro "Desenho Linear ou Elementos de Geometria Prática Popular seguidos de algumas noções de agrimensura, stereometria e architectura para uso das Escolas primárias e normaes, dos Lyceus e Collegios, dos Cursos de adultos, e em geral dos artistas e operarios em qualquer ramo de indústria", 1882, escrito por Abílio Cesar Borges ${ }^{5}$, Barão de Macahubas.

Trata-se da primeira parte destinada exclusivamente às escolas primárias, conforme esclarece o autor no prólogo da segunda versão. Na introdução, o autor compara o Desenho à escrita, afirmando que: “Ao deixar a escola primária deveriam os meninos saber tanto de desenho como de escripta, isto é, escrever uma idéa ou um objecto por meio de linhas e sombras, como sabem fazel-o por meio da escripta abstracta ordinaria" (BORGES, 1882, p. $\mathrm{X})$.

A longa introdução, escrita em Paris em 1878, traz diversos argumentos citando educadores, inspetores e sistemas educativos de vários países europeus e dos Estados Unidos para reforçar a defesa da importância do ensino do desenho na visão do próprio autor.

\footnotetext{
${ }^{5}$ Mais informações sobre o autor podem ser consultadas em Trinchão (2007).
} 
DOI: $10.20396 /$ zet.v27i0.8654266

Procura-se mostrar a necessidade do desenho no processo de industrialização da Inglaterra e da França. Citando Tronquoy, professor de desenho de máquinas da École Polythecnique de Paris, Borges (1882) transcreve

Diante das exigências sempre crescentes da industria, dos progressos da mechanica e das artes, que teem connexão com as sciencias mathematicas, o conhecimento do desenho geométrico é tão indispensável ao engenheiro e ao architecto como ao artista, e ao operario; e é util, pelo menos, ao homem do mundo, que não quer ser completamente estranho ao desenvolvimento industrial de seu tempo (TRONQUOY, apud BORGES, 1882, p. XII).

Essa primeira parte aborda figuras planas e sólidos. A geometria é estudada sem que as construções sejam mencionadas, sejam com instrumentos ou sem. Ao final, constam os exercícios gráficos, figuras como a representada a seguir, sem nenhuma instrução ou enunciado relacionado.

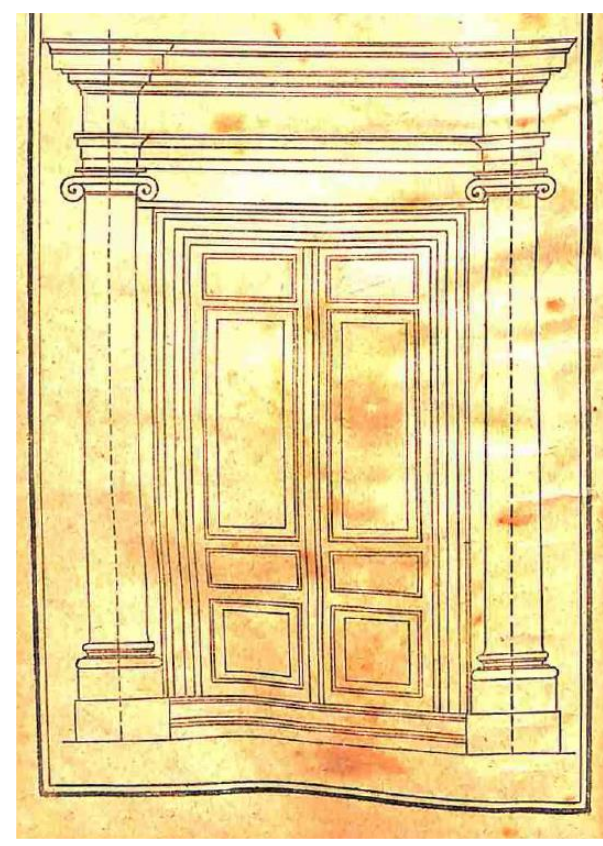

Figura 3: exercício gráfico

Fonte: Borges, 1882

Duas inovações, frente às obras anteriormente analisadas, são a introdução de um questionário e de um quadro sinótico ao final de cada capítulo. As qualidades didáticas da obra são apresentadas em duas cartas de amigos do autor, em resposta ao envio da obra pelo mesmo. Ambas comentam que jovens que leram o livro aprenderam facilmente a geometria. Cabe mencionar que o acervo de obras da professora Alda Lodi ${ }^{6}$, importante educadora mineira entre as décadas de 1920 e 1950, contém um exemplar deste livro.

Os elementos de profissionalidade presentes nessa obra dizem respeito à Geometria a ensinar. As características, classificações e propriedades das figuras planas e dos corpos -

\footnotetext{
${ }^{6}$ Para maiores informações sobre a atuação da professora e sua relação com a formação de professores primários sob a perspectiva da educação matemática, consultar Reis (2014).
} 
DOI: $10.20396 /$ zet.v27i0.8654266

poliedros e corpos redondos - são abordadas sem indicações de ordem metodológica. Os exercícios gráficos que completam o livro ao final parecem servir de modelos para serem coloridos ou reproduzidos pelos alunos, não há indicações ou sugestões de como trabalhar com tais figuras.

Guimarães (2016) analisando as obras de Desenho Linear de d'Albuquerque (1829), Gama (1880), Pacheco (1881) e Borges (1882) atribui a elas uma perspectiva de caráter elementar para o saber desenho. Ou seja, o desenho teria a finalidade de introduzir um saber científico, numa perspectiva propedêutica do ensino, no caso a geometria. Tais considerações tomam como referência duas correntes pedagógicas antagônicas na compreensão dos saberes elementares: a que baseia esses saberes nos elementos e a que baseia nos rudimentos. Segundo Valente (2016), a perspectiva dos elementos ou elementar vislumbra uma formação propedêutica, onde os saberes iniciais devem preparar para a formação secundária ou científica. Para isso, a abstração e a generalização são constituintes importantes do ensino. Enquanto a perspectiva rudimentar pressupõe como finalidade para o ensino primário a preparação para a vida. Dessa forma, a experimentação e a aplicação no cotidiano, na vida prática determinam o tratamento dado aos saberes a ensinar.

Contudo é possível ponderar que, dado o apelo presente em quase todos os prefácios e introduções das quatro obras em torno da importância do Desenho Linear para o trabalho na indústria, na engenharia, na arquitetura, os saberes ali sistematizados eram vistos como rudimentos, na medida em que preparariam para o exercício profissional.

\section{Conclusões}

O que os quatro livros têm em comum em termos de profissionalidade? O Desenho Linear a ensinar em todos eles refere-se ao estudo das figuras planas - linhas, polígonos e curvas -; e dos poliedros e corpos redondos, sem a preocupação com o cálculo de grandezas, como perímetro, área e volume. O estudo das figuras geométricas é destacado em termos da construção (com ou sem instrumentos) sendo uma atividade manual formativa, de mesma importância que a escrita. E ainda, conhecer, construir e compor mosaicos com figuras geométricas desenvolve o gosto pelo belo, prepara para a formação profissional na indústria.

O Desenho Linear cumpria assim um duplo papel: contribuir no desenvolvimento dos alunos articulando a dimensão física e intelectual; e preparar para a futura atuação profissional. O peso desse duplo papel na formação das crianças e a relação com estes conteúdos de geometria nos leva a pensar no lugar que determinados saberes ocupam na educação a partir de um processo de construção histórico de seu significado para a formação das futuras gerações.

As marcas específicas de cada uma das obras analisadas ficam mais evidentes no que diz respeito às questões metodológicas - Desenho Linear para ensinar. O manual de d'Albuquerque (1829) apresenta uma proposta para o ensino de Desenho Linear segundo o método do ensino mútuo. Detalha a forma como os decuriões deveriam fazer as correções dos exercícios executados pelos alunos, os cuidados na apresentação da proposta de trabalho e o 
DOI: $10.20396 /$ zet.v27i0.8654266

silêncio sobre a maneira de realizar a tarefa. O livro de Gama (1880) propõe o estudo das figuras de forma articulada à construção das mesmas utilizando instrumentos. Pacheco (1881) faz em capítulos diferentes o estudo das figuras e a construção das mesmas, não relacionando tais aspectos. A obra de Borges aqui analisada é dedicada aos alunos da escola primária; nela não está proposto o uso dos instrumentos. Pode-se observar a preocupação do autor em ajustar o conteúdo e o método de ensino para o primário, diante de uma publicação anterior que contemplava vários segmentos da instrução: além das escolas primárias e normais, cursos de adultos para artistas e operários em qualquer ramo de indústria.

O uso ou não dos instrumentos de desenho estabelece uma diferenciação metodológica, que implica em diferentes saberes para ensinar Desenho Linear. Em cada uma das obras o uso dos instrumentos pressupõe concepções sobre o saber a ensinar, as formas geométricas, que diferem pela forma como os instrumentos são mobilizados para o ensino. Por exemplo, articular a construção das figuras com as propriedades das mesmas, como faz Gama, explora a vinculação entre a geometria e a construção geométrica herdeira dos Elementos de Euclides.

\section{Referências}

Albuquerque, A. F. de P. I. C. (1829). Principios do Desenho Linear Comprehendendo os de Geometria Pratica pelo Methodo do Ensino Mutuo. Rio de Janeiro: Imperial Typ. P. Plancher-Seignot. Retirado em 18 de maio, 2018 de: https://repositorio.ufsc.br/bitstream/handle/123456789/159257/PRINCI\%CC\%81PIOS\% 20DO\%20DESENHO\%20LINEAR\%20-\%201829..pdf?sequence=1\&isAllowed=y .

André, M. E.D.A. \& Almeida, P. A. (2010). A Profissionalidade dos professores de licenciatura sob o impacto das reformas educativas e das mudanças no mundo contemporâneo. In: $\mathrm{R}$ Ens \& $\mathrm{M}$. Behrens (Org.). Formação do professor: profissionalidade, pesquisa e cultura escolar (pp. 75-96). Curitiba: Champagnat.

Borer, V. (2017). Saberes: uma questão crucial para a institucionalização da formação de professores. In R. HOFSTETTER \& W. R. VALENTE. Saberes em (trans)formação: tema central da formação de professores (pp. 173 - 200). São Paulo: Livraria da Física.

Borges, A. C. (1882). Desenho Linear ou Elementos de Geometria Pratica Popular seguidos de algumas noções de Agrimensura, Stereometria e Architectura para uso das Escolas primarias e normaes, dos Lyceus e Collegios, dos Cursos de adultos, e em geral dos artistas e operarios em qualquer ramo de industria. Rio de Janeiro: Typ. Aillaud, Alves $\&$ Cia. $8^{\text {a }}$. ed. Retirado em 18 de maio, 2018 de: < https://repositorio.ufsc.br/handle/123456789/159272>.

Bourdoncle, R. (1991). La professionnalisation des enseignants: analyses sociologiques anglaises et américaines. Revue Française de Pédagogie, (94), 73-92.

D’Enfert, R. (2007). Uma nova forma de ensino de desenho na França no início do século XIX: o desenho linear. Tradução Maria Helena Câmara Bastos. História da Educação. ASPHE/UFPe, (22), 31-60. 
DOI: $10.20396 /$ zet.v27i0.8654266

Gama, A. A. (1880). Elementos de Desenho Linear. Rio de Janeiro: B. L. Garnier, Livreiro Editor. $2^{\mathrm{a}}$. ed. melhorada. Retirado em 18 de maio, 2018 de: < https://repositorio.ufsc.br/handle/123456789/159275>.

Guimarães, M. D. (2016). O Desenho a ensinar em Rui Barboa: elementos ou rudimentos? Anais do III ENAPHEM (pp. 363-375). São Mateus: SBHMat. Retirado em 18 de maio, 2018 de: https://repositorio.ufsc.br/handle/123456789/171651.

Hofstetter, R. \& Schneuwly, B. (2009). Savoirs en (trans)formation: Au coeur des professions de l'enseignement et de la formation. Bruxelas: De Boeck.

Hofstetter, R. \& Schneuwly, B. (2017). Saberes: um tema central para as profissões do ensino e da formação. In HOFSTETTER, R.\& VALENTE, W. R. Saberes em (trans)formação: tema central da formação de professores (pp. 113 - 172). São Paulo: Livraria da Física.

Le Goff, J. (1992). História e Memória. Campinas, SP: Editora da Unicamp.

Lei de 15 de outubro de 1827. (1827). Criação de Escolas de Primeiras Letras em todas as cidades, villas e logares mais populosos do Imperio. Retirado em 18 de maio, 2018 de: <https://repositorio.ufsc.br/handle/123456789/99972>.

Lei $n^{\circ} 16$, de 12 de Agosto de 1834. (1834). Faz algumas alterações e adições à Constituição Política do Império, nos termos da Lei de 12 de outubro de 1832. Retirado em 18 de maio, 2018 de: <http://www2.camara.leg.br/legin/fed/lei/1824-1899/lei-16-12-agosto1834-532609-publicacaooriginal-14881-pl.html>

Oliveira, M. C. A. (2015a). Profissionalidade para o ensino de Geometria: Um estudo a partir da legislação. Revista de História da Educação Matemática - HISTEMAT, 1 (1), 189 202. Retirado em 18 de maio, 2018 de: http://www.histemat.com.br/index.php/HISTEMAT/article/view/14

Oliveira, M. C. A. (2015b) Geometria e Desenho como matérias do Curso Normal no período da Primeira República no Brasil. Interfaces Científicas - Educação, 3 (2), 43-54. Retirado em 18 de maio, 2018 de: https://periodicos.set.edu.br/index.php/educacao/article/view/1974

Oliveira, M. C. A. (2016). Elementos de profissionalidade para uma Geometria moderna: normativas oficiais e manuais pedagógicos como referenciais para a prática docente. Revista de História da Educação Matemática - HISTEMAT, 2 (1) , 60-71. Retirado em 18 de maio, 2018 de: http://www.histemat.com.br/index.php/HISTEMAT/article/view/58/30

Oliveira, M. C. A. (2018). Cadernos de Trabalho II - Profissionalização/Profissionalidade. São Paulo: Livraria da Física. Volume 5.

Pacheco, P. M. (1881). Curso Elementar de Desenho Linear. Rio de Janeiro: Imprensa Industrial,. Retirado em 18 de maio, 2018 de: < https://repositorio.ufsc.br/handle/123456789/159295>.

Reis, D. A. F. (2014). História da formação de professores de Matemática do ensino primário em Minas Gerais: estudos a partir do acervo de Alda Lodi (1927 a 1950). Tese de Doutorado em Educação. Belo Horizonte: Universidade Federal de Minas Gerais.

Saviani, D. (2009). Formação de professores: aspectos históricos e teóricos do problema no contex to brasileiro. Revista Brasileira da Educação, 14(40), 143-155. 
DOI: $10.20396 /$ zet.v27i0.8654266

Tanuri, L. M. (2000). História da Formação de Professores. Revista Brasileira de Educação, (14), $61-88$.

Trinchão, G. M. C. (2007). O conhecimento em Desenho das Escolas Primárias Imperiais brasileiras: o livro de desenho de Abílio César Borges. Revista História da Educação, 11 (23), 125-147. Retirado em 18 de maio, 2018 de: http://seer.ufrgs.br/asphe/article/view/29274.

Valente, W. R. (2011). A matemática na formação do professor do ensino primário em São Paulo, 1875-1930. São Paulo: Editora Anna Blume.

Valente, W. R. (2016). A Matemática nos primeiros anos escolares: elementos ou rudimentos? Revista História da Educação, 20 (49), 33-47. Retirado em 18 de maio, 2018 de: http://www.scielo.br/scielo.php?script=sci_arttext\&pid=S2236$34592016000200033 \& \operatorname{lng}=\mathrm{en} \& \mathrm{nrm}=\mathrm{iso} \& \operatorname{lng}=\mathrm{pt}$

Valente, W. R. (2017). A matemática a ensinar e a matemática para ensinar: os saberes para a formação do educador matemático. In HOFSTETTER, R.; VALENTE, W. R. Saberes em (trans)formação: tema central da formação de professores (pp. 201 - 228). São Paulo: Livraria da Física. 